Vol. 23 N.1 de 2020 ISSN: 1516-8182

Recebimento: 02/10/2019

Aceite: 18/12/2019

DOI: 10.25059/2527-2594/retratosdeassentamentos/2020.v23i1.362

\title{
Infraestrutura e assistência técnica e extensão rural em assentamentos do Cariri Cearense: fatores limitantes para o acesso ao programa nacional de alimentação escolar
}

\author{
Juscelino Martins Costa Junior ${ }^{1}$ \\ Vanilde Ferreira de Souza-Esquerdo ${ }^{2}$ \\ Sonia Maria Pessoa Pereira Bergamasco ${ }^{3}$ \\ Ricardo Serra Borsatto ${ }^{4}$
}

Resumo:Este trabalho buscou verificar como a infraestrutura e os serviços de Assistência Técnica e Extensão Rural (ATER) afetam a participação dos assentados do território da cidadania do Cariri - Ceará junto ao Programa Nacional de Alimentação Escolar (PNAE). A pesquisa foi realizada nos assentamentos federais do território da cidadania do Cariri, localizado no sul do estado do Ceará. Como metodologia foi realizado um estudo de natureza quantitativa e qualitativa, com a aplicação de questionários semiestruturados e entrevistas não estruturadas, além de métodos de observação participativa para melhor compreender a realidade dos assentados. Os assentamentos apresentam vias de acesso precárias, bem como poucos equipamentos públicos como hospitais, praças, ou escolas em suas proximidades. Pelas características dos assentamentos, os assentados enfrentam diversas dificuldades na comercialização dos seus produtos. O PNAE oferece um mercado institucional capaz de absorver parte da produção dos assentados, porém poucos assentados conseguem acessar esse canal para escoar sua produção. O baixo acesso ao programa está vinculado a ausência de infraestrutura nos assentamentos, às características ambientais locais e à falta de assistência técnica e extensão rural aos assentados. Concluímos que o PNAE tem potencial para a promoção do desenvolvimento rural nos assentamentos, mas que é necessária uma atuação mais constante de órgãos de assistência técnica e extensão rural para a promoção dos serviços de infraestruturas.

Palavras-Chave: Desenvolvimento Rural. Políticas Públicas. Reforma Agrária.

INFRASTRUCTURE AND TECHNICAL ASSISTANCE AND RURAL EXTENSION IN CARIRI CEARENSE SETTLEMENTS: LIMITING FACTORS FOR ACCESS TO THE NATIONAL SCHOOL MEAL PROGRAM

ABstraCt:This work sought to verify how the infrastructure and services of Technical Assistance and Rural Extension (ATER) affect the participation of the settlers in the territory of the citizenship of Cariri - Ceará with the National School Food Program (PNAE). The research was carried out in the federal settlements of the territory of the citizenship of Cariri, located in the south of the state of Ceará. As a methodology, a quantitative and qualitative study was carried out, with the application of semi-structured questionnaires and unstructured interviews, in addition to participatory observation methods to better understand the reality of the settlers. The settlements have poor access roads, as well as few public facilities such as hospitals, squares, or schools in their vicinity. Due to the characteristics of the settlements, the settlers face several difficulties in the marketing of their products. PNAE offers an institutional market capable of absorbing part of the settlers'

\footnotetext{
${ }^{1}$ Doutorando em Desenvolvimento rural sustentável. Universidade Estadual do Oeste do Paraná, UNIOESTE, Brasil.E-mail: juscelinojunior_@hotmail.com

${ }^{2}$ Docente na Faculdade de Engenharia Agrícola/UNICAMP. E-mail: vanilde.esquerdo@feagri.unicamp.br

${ }^{3}$ Docente na Faculdade de Engenharia Agrícola/UNICAMP. E-mail: sonia@feagri.unicamp.br

${ }^{4}$ Docente na Universidade Federal de São Carlos/ UFScar. E-mail: rsborsat@gmail.com
} 
production, however few settlers are able to access this channel to drain their production. Low access to the program is linked to a lack of structure in the settlements, local environmental characteristics and the lack of technical assistance and rural extension to the settlers. We conclude that PNAE has the potential to promote rural development in the settlements, but that more constant action by technical assistance and rural extension bodies is needed, favoring family farming.

Keywords: Rural Development. Public Policy. Land Reform.

\section{INTRODUÇÃo}

Desde as décadas de 1950 e 1960, a reforma agrária vem sendo discutida nas mais amplas esferas (política, acadêmica e sociedade em geral) por ser uma política tida como uma das soluções para muitos dos problemas nacionais, porém somente na década de 1980 registra-se a criação de assentamentos rurais em todas as unidades federativas do Brasil, implementação esta que aconteceu de forma lenta e irregular (BERGAMASCO, 1997). Bergamasco e Norder (1999, p. 7) conceituam os assentamentos rurais como "a criação de novas unidades de produção agrícola, por meio de políticas governamentais visando o reordenamento do uso da terra, em benefício de trabalhadores rurais sem terra ou com pouca terra., esse novo espaço produtivo gera impactos na economia e na sociedade como um todo, necessitando vir acompanhados de políticas agrícolas, em especial a de crédito rural e assistência técnica (SPAROVEK, 2003).

Ao longo do tempo, as políticas agrícolas privilegiavam os grandes proprietários de terra, bloqueando as possibilidades de desenvolvimento da agricultura familiar. Somente a partir da década de 1990, especialmente com a criação do Programa Nacional de Fortalecimento da Agricultura Familiar (PRONAF), houve um olhar mais atento por parte do Estado à agricultura familiar (DENARDI, 2001; PRETTO, 2020; FEUSER, 2019).

Um dos principais entraves para os assentados rurais refere-se à comercialização dos seus produtos. O estabelecimento de programas de políticas públicas que possibilitem o acesso aos mercados institucionais se apresenta como alternativa para aproximar a produção de base familiar ao consumo. Um destes programas é o Programa Nacional de Alimentação Escolar - PNAE, que por meio da Lei n. 11.947 de 2009, estabeleceu a obrigatoriedade de aquisição de no mínimo 30\% de alimentos oriundos da agricultura familiar para a merenda escolar (SOUZAESQUERDO; BERGAMASCO, 2014; SCHNEIDER, GERHARDI, TRICHES, 2008; BRASIL, 2009; BURLANDY, 2009; TRICHES, SCHNEIDER, 2010; VILLA REAL, SCHNEIDER, 2011; MELÃO, 2012). 
Mesmo a Lei 11.947/2009 sendo um importante mecanismo para a segurança alimentar e nutricional dos estudantes, bem como instrumento de fortalecimento da agricultura familiar, diversos municípios e estados ainda não conseguiram atingir o percentual mínimo de $30 \%$ de compra dos alimentos da agricultura familiar para a alimentação escolar (SARAIVA et. al, 2013). Em 2017, último ano de atualização de dados do PNAE, 53,1\% dos estados da região Norte; 23,3\% do Nordeste; $6,1 \%$ do Sudeste; $11,2 \%$ do Sul; e 9,5 do Centro-oeste, compraram produtos oriundos da agricultura familiar para a alimentação escolar (FNDE, 2018).

A aquisição de alimentos da agricultura familiar por intermédio do Programa Nacional de Alimentação Escolar é uma ação que impõe desafios para as organizações envolvidas, pois possui complexidade própria, além disso, apresenta uma cadeia de especificidades, envolve uma multiplicidade de profissionais e arranjos institucionais (CORÁ; BELIK, 2012).

Por todo o exposto, este trabalho objetivou verificar como a infraestrutura e os serviços de assistência técnica e extensão rural podem interferir para que assentados do território da cidadania do Cariri - Ceará comercializem sua produção para o Programa Nacional de Alimentação Escolar - PNAE.

Este trabalho está dividido em cinco seções além desta introdução. Na segunda seção, foi realizada uma revisão bibliográfica sobre a reforma agrária no Ceará e, consequentemente, no Cariri cearense; na terceira seção descrevemos a metodologia utilizada para a coleta de dados. Posteriormente, na quarta seção, apresentamos os resultados e a discussão sobre o tema central, abrangendo a caracterização dos assentamentos federais pesquisados; e, por último, tecemos algumas considerações finais.

\section{A questão agrária no estado do Ceará}

Os processos de ocupação dos estados nordestinos tiveram o contexto histórico ligado ao período em que o país estava imerso, ainda como província, com a doação de terras por meio das sesmarias. Além deste contexto, um dos principais aspectos da ocupação das terras cearenses foi a entrada de baianos e pernambucanos por meio da pecuária que formaram grandes fazendas e se apropriaram de grandes extensões do sertão nordestino. Foram os grandes latifundiários pecuaristas que dominaram a área, os latifúndios ocupavam centenas de quilômetros de extensão, onde se fazia a pecuária ultraextensiva, em campo aberto para a produção de carne e de animais de trabalho que eram vendidos inicialmente para as áreas canavieiras de Pernambuco e da Bahia e, a partir do século XVIII, para Minas Gerais (ANDRADE, 2004).

Conforme Andrade (1994), era destacada a venda de animais para locais 
com produção de açúcar, tão presente no Ceará da época, além da venda para a produção de carne de charque. Sempre representada por grandes áreas nas mãos de poucos e pequenas áreas de terra nas mãos de muitos, representando enorme desigualdade social.

As primeiras experiências de organização camponesa, no Ceará, datam dos anos 1950, quando o movimento social dos trabalhadores rurais começou a consolidar sua organização com a criação da União dos Lavradores e Trabalhadores Agrícolas do Ceará (ULTAC), tempos depois, em 1957, transformada em Federação das Associações de Lavradores e Trabalhadores Agrícolas do Ceará (FALTAC). A partir da década de 1960 e, especialmente, na década de 1970, o campo cearense foi alvo de profundas fissuras nas relações sociais tradicionalmente mantidas entre fazendeiro/patrão e camponês/trabalhador, lutas que marcam a história agrária do estado. Essas décadas apresentaram grande período de seca no Ceará, agravando ainda mais a situação dos agricultores (ESPLAR, 1991 apud GOVERNO DO ESTADO, 2014).

Os principais agentes envolvidos na luta pela reforma agrária no estado têm sido a Igreja Católica, via Comunidades Eclesiais de Base (CEBs) e da Comissão Pastoral da Terra (CPT), o Movimento dos Trabalhadores Rurais Sem Terra (MST) e os Sindicatos dos Trabalhadores Rurais (STRs), que pressionam o poder público pela desapropriação de novas áreas por meio das ocupações de terra e acampamentos.

De acordo com Barreira (1992), essas lutas se apresentavam de uma forma isolada, dentro de contornos geográficos bem precisos, são lutas locais que deixaram suas marcas na história cearense no interior de cada fazenda e guardam como característica comum o confronto direto entre camponeses e latifundiários.

Apesar da luta pela terra estar presente em todas as regiões do estado do Ceará, do litoral até os seus interiores, uma região que sofreu significativas mudanças por esses processos foi o Cariri cearense, que possui muitas peculiaridades em relação ao restante do estado, especialmente por seus aspectos ambientais, econômicos e religiosos.

O Cariri cearense se caracteriza por um grande número de propriedades com tamanho extremamente reduzido, oriundas de grandes latifúndios que foram se subdividindo e gerando áreas pequenas, que juntas ocupam pequena porcentagem das terras agricultáveis. A quantidade de imóveis rurais considerados minifúndios é muito maior do que as grandes propriedades. O estado do Ceará possui 1.610 imóveis considerados como grandes propriedades, por outro lado, possui 119.335 considerados minifúndios, estes últimos ocupam uma área de 1.948 .845 ha, enquanto as áreas de grandes propriedades possuem ao todo 2.541 .809 ha, 
demonstrando assim a concentração fundiária neste estado (IBGE, 2017).

Essas áreas menores estão presentes em todo o Cariri cearense, pelo fato desta região apresentar a agricultura como a principal atividade no campo, seja para o autoconsumo ou para a comercialização. Segundo Brígido (2001), as primeiras concessões de sesmarias no Cariri ocorreram por volta dos anos de 1700 e foram dadas pelos senhores da Casa da Torre ${ }^{5}$. Da mesma forma como ocorreu no restante do estado do Ceará, a região do Cariri também foi povoada pelo ciclo do gado, que percorreu todo o sertão. No caso do Cariri, eram atraídos pelo "Oásis no meio do deserto", já que esta região é cercada pro uma área de Mata Atlântica, cheia de nascentes e de rios, uma ótima opção para o manejo do gado.

Petrone (1955, p. 10), cita que

“ [...] com o povoamento iniciado na base da criação de gado em grandes propriedades, a região do Cariri viu suas terras se subdividirem em propriedades menores graças à parcial substituição da criação pela agricultura, consequente ao paralelo aumento da população e fragmentação da terra por herança" (PETRONE, 1955,p.10).

O povoamento recente do Cariri também está ligado à estrutura religiosa, já que o município de Juazeiro do Norte, que possui o maior número de habitantes entre os 28 da região, desde a década de 1920, recebe muitos "romeiros" do Padre Cicero, figura religiosa bastante importante para a história da região.

Conforme o tempo foi passando e o processo de reforma agrária foi sendo reconhecido, foi analisado que não apenas a concessão de terras seria uma forma de fortalecer o agricultor familiar, mas que esta deveria vir acompanhada de outras políticas públicas capazes de fortalecer a manutenção do agricultor na terra.

As políticas públicas são imprescindíveis para a manutenção dos agricultores assentados no seu espaço social. Pesquisas mostram (SANTOS, 2012; FINATTO, 2010) a dificuldade de comercialização de produtos oriundos da agricultura familiar, podendo desestimular a produção agrícola e, consequentemente, a vida no meio rural. Nos anos 2000, programas de políticas públicas foram implementados para fortalecer a agricultura familiar instituindo-se um mercado governamental para os seus produtos. Neste sentido, dois programas são destacados, o Programa de Aquisição de Alimentos e o Programa Nacional de Alimentação Escolar, este último com a sua reformulação por meio da Lei 11.947/2009.

\footnotetext{
${ }^{5}$ A Casa da Torre também conhecida como Casa da Torre de Garcia d’Ávila, Castelo de Garcia d'Ávila, Torre de Garcia d’Ávila, Forte de Garcia d’Ávila além de uma construção histórica, era um império dono de grandes áreas de terra, que teve sua expansão ao longo das gerações dos seus senhores por mais de 400 léguas na Região Nordeste do Brasil um território correspondente ao dobro da capitania do Piauí. Eles realizavam guerras contra os índios e os escravizavam para trabalharem nas plantações de cana-de-açúcar e nas criações de gado, criações estas que foram o ponto forte para a colonização do Nordeste. A casa da Torre criou grande um império de terras pelo Nordeste (BANDEIRA, 2000).
} 
O PNAE apresenta diversos fatores limitantes para que o objetivo da Lei 11.947 seja alcançado, dentre eles podemos citar: ausência de ATER; falta de conhecimento dos agricultores sobre as documentações necessárias para sua participação no PNAE; e dificuldades estruturais (CAMARGO et al., 2013; CRUZ, 2019; SILVA et al., 2013).

Os serviços de ATER são uma ponte importante entre os agricultores e os mercados institucionais, os seus agentes compartilham informações importantes e são também motivadores para o processo de adesão ao PNAE. Ademais, é um serviço primordial para o auxílio das atividades agrícolas e organizacionais dos agricultores, gerando um arranjo importante para a comercialização dos alimentos. A falta de conhecimento dos agricultores sobre as documentações necessárias para a participação no PNAEéum fator que está atrelado aos serviços de ATER, cuja falta pode ser limitante para a participação de assentados no programa (SOUZA-ESQUERDO; BERGAMASCO, 2014).

Associado à falta de ATER, questões relacionadas à infraestrutura também podem afetar a participação de assentados no PNAE. Na maioria dos casos, os assentamentos são implementados em espaços sem uma infraestrutura, demorando muitos anos para formar uma infraestrutura básica. A participação em políticas públicas que necessitam de produção agrícola constante, necessita também de serviços de infraestrutura e de ATER para o bom desempenho. A sua falta representa uma dificuldade a mais para esse público, os principais entraves associados à infraestrutura referem-se, principalmente, à logística de apoio, como transporte, beneficiamento e armazenamento dos alimentos (SAMBUICHI et al., 2014).

Em regiõesáridase semiáridas do Nordestebrasileiro, a faltadeATEReinfraestrutura nos assentamentos podem ser agravadas pelas condições edafoclimáticas, pois a ausência de chuvas representa importante barreira para a produção de alimentos.

\section{Metodologia}

\section{ÁREA DE ESTUdo}

O campo de análise deste artigo refere-se ao território da cidadania do Cariri, que conta com 28 municípios, correspondendo a uma área de 16.350,40 km² e está localizado na região sul do estado do Ceará, zona semiárida, tendo como limites: ao sul, o estado de Pernambuco; à oeste, o estado do Piauí; à leste, o estado da Paraíba e ao norte, os municípios de Aiuaba, Saboeiro, Jucás, Cariús, Cedro, Lavras da Mangabeira e Ipaumirim (BRASIL/MDA, 2010).

No território da cidadania do Cariri há 37 assentamentos rurais com 856 famílias assentadas, o que corresponde a 10,78\% dos assentamentos do estado, abrigando $4,47 \%$ do total de famílias assentadas. Seis desses assentamentos são federais e estão localizados em municípios de pequeno e médio porte: o assentamento São João e o assentamento São Paulo, localizados em Antonina do Norte; o Baixa 
Grande, localizado em Jati; o Olho D água, em Várzea Alegre; o assentamento Serra Verde, localizado em Caririaçu e o ACOCI; em Campos Sales (BRASIL, 2010; INCRA, 2018).

O território pode ser subdividido em microterritórios, sendo eles: Leste, Central e Oeste. Esses microterritórios serviram como base para a aplicação da metodologia e definição da amostragem dos assentamentos estudados. Para esta pesquisa, foram selecionados quatro assentamentos, abrangendo os três microterritórios, para que assim tivéssemos uma representação do território em termos de assentamentos rurais. Os assentamentos escolhidos foram: Assentamento São João e Assentamento São Paulo, localizados no município de Antonina do Norte, no microterritório do Cariri Oeste; o Assentamento Baixa Grande, localizado no município de Jati, microterritório do Cariri Leste; e o Assentamento Olho D’água. localizado no município de Várzea Alegre, microterritório do Cariri Central (Figura 1).

Figura 1 - Localização dos municípios que possuem os assentamentos pesquisados dentro do Território da Cidadania do Cariri, Ceará.

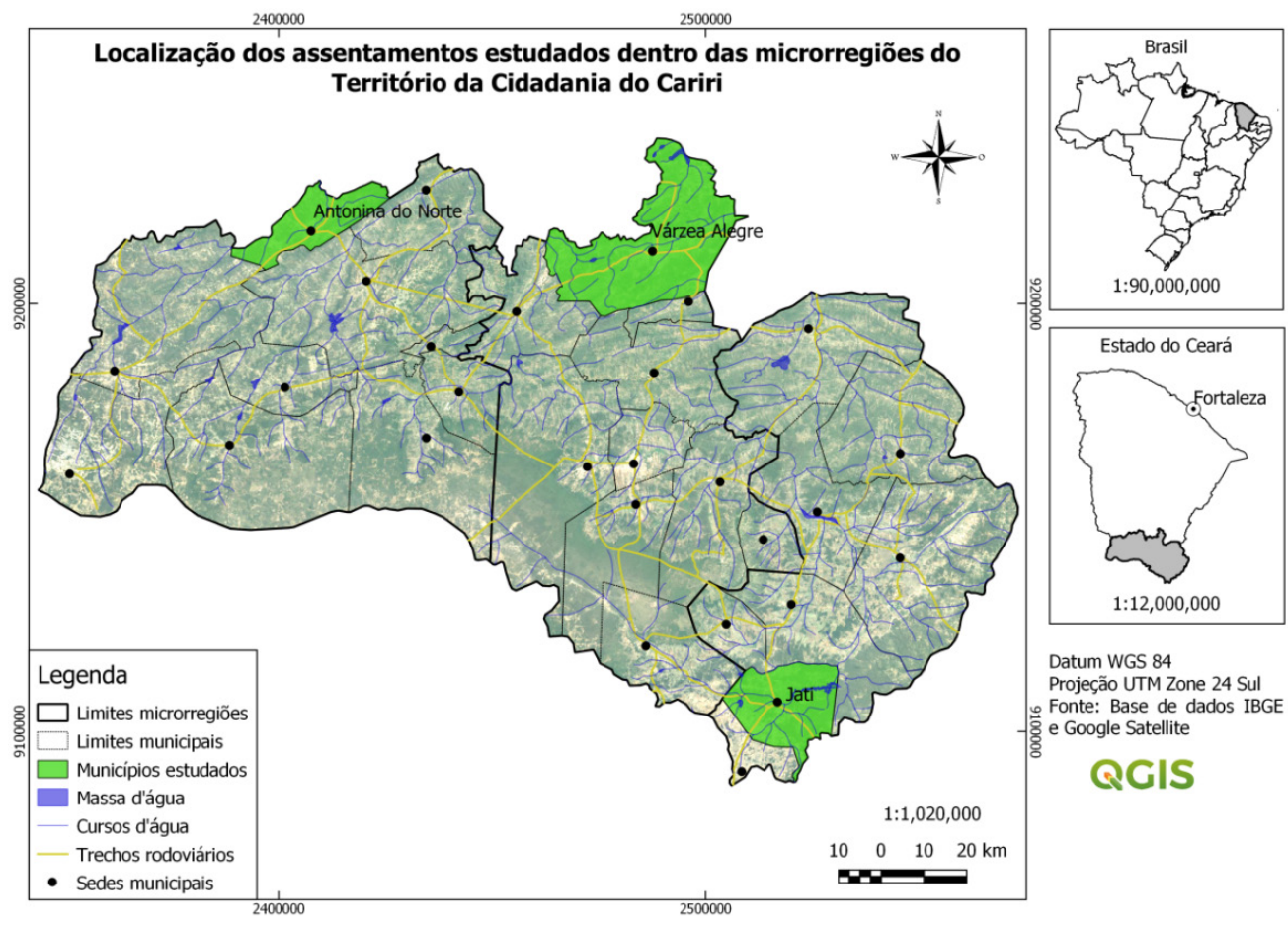

Fonte: Elaborado pelo primeiro autor. 
Foi realizado um estudo de natureza quantitativa e qualitativa, com a aplicação de questionários semiestruturados com questões abertas e fechadas (GIL, 2002). Os questionários envolveram questões voltadas à identificação das políticas públicas acessadas pelos agricultores familiares dos quatro assentamentos rurais estudados. Questões sobre a infraestrutura do assentamento e características produtivas também foram abordadas.

Foram utilizados métodos de observação participante para melhor compreender a realidade dos assentados. O uso do diário de campo foi muito importante para o registro de informações que não foram captadas pelos questionários, pois trata-se de uma técnica de pesquisa onde o pesquisador anota as suas impressões sobre suas incursões ao campo investigado.

Também foram realizadas entrevistas não estruturadas com agentes locais envolvidos na execução do PNAE. Desta forma, foram realizadas entrevistas com secretários e coordenadores do PNAE das secretarias de educação dos municípios estudados. Essas entrevistas tiveram por objetivo analisar a atuação dos municípios no PNAE e sua relação com os assentamentos rurais.

Após um primeiro contato com os assentamentos federais do território da cidadania do Cariri, foi realizada a pesquisa de campo nos assentamentos selecionados. A aplicação dos questionários foi realizada nos meses de maio e junho de 2018. Por último, foram realizadas entrevistas não estruturadas com os secretários de agricultura dos municípios estudados, com o objetivo de compreender como ocorre o serviço de Assistência Técnica e Extensão Rural nos assentamentos.

Tabela 1 - Número de famílias assentadas e entrevistadas na pesquisa.

\begin{tabular}{lllll}
\hline Assentamento & Ano de Criação & Município & $\begin{array}{l}\text { No de famílias } \\
\text { assentadas }\end{array}$ & $\begin{array}{l}\text { No de famílias en- } \\
\text { trevistadas }\end{array}$ \\
\hline São João & 2002 & Antonina do Norte & 18 & 11 \\
\hline São Paulo & 2010 & Antonina do Norte & 08 & 05 \\
\hline Olho D’ água & 1996 & Várzea Alegre & 19 & 14 \\
\hline Baixa Grande & 2009 & Jati & 144 & 17 \\
\hline Total & & & & 47 \\
\hline
\end{tabular}

Fonte: Elaborado pelos autores a partir dos dados do INCRA (2019).

Os assentamentos São João, São Paulo e Olho D’água possuem poucas famílias assentadas, desta forma a meta era realizar a aplicação do questionário com todos os assentados, porém alguns deles não se encontravam em seus lotes nos dias da pesquisa. No caso do assentamento Baixa Grande, devido ao grande número de assentados foi realizada uma amostragem que representasse a totalidade dos as- 
sentados, essa amostragem foi calculada pela fórmula (SANTOS, 2018):

$$
n=N Z^{2} p(1-p) /(N-1) e^{2}+Z^{2} p(1-p)
$$

n é o tamanho da amostra que queremos calcular, cujo resultado foi de 17 famílias;

$\mathbf{N}$ é tamanho do universo, no nosso caso foi 144 , que é o total de lotes do assentamento;

$\mathbf{Z}$ é o desvio do valor médio que é aceito para alcançar o nível de confiança desejado, foi usado $95 \%$;

e é a margem de erro máximo que é admitida, no nosso caso foi usado $10 \%$;

$\mathbf{p}=$ a proporção que se espera encontrar.

Os assentados foram entrevistados e no texto foram denominados de acordo com o número da sua entrevista.

\section{RESULTADOS E DISCUSSÃo}

\section{CONHECENDO OS ASSENTAMENTOS ESTUDADOS}

\section{- Assentamento São João}

O assentamento São João está localizado no município Antonina do Norte, microterritório do Cariri Oeste e possui 18 famílias assentadas. Em 2000, as famílias montaram acampamento na área, porém somente após dois anos de disputas, o assentamento foi implementado pelo governo federal dentro do Programa Nacional de Reforma Agrária no ano de 2002.

Neste assentamento, os assentados possuem em média 45 anos, oriundos, em sua maioria, do próprio município de Antonina do Norte, os poucos que não são deste município têm origem em municípios próximos. Todos residem no assentamento e possuem uma média de escolaridade baixa, onde a grande maioria possui o ensino fundamental incompleto. Todos os assentados pesquisados possuem como principal ocupação a atividade agropecuária, que consiste no manejo de ovinos e caprinos e na produção de milho e feijão, que são as principais culturas utilizadas pela agricultura familiar no Nordeste. $\mathrm{O}$ assentamento possui um grande açude, que em períodos de estiagem costuma proteger a população da crise hídrica, mas que entre 2012 e 2018 não conseguiu ficar cheio devida a seca, diminuindo a produção dos assentados.

\section{- Assentamento São Paulo}

O assentamento São Paulo também está localizado no município de Antonina do Norte. Este assentamento que já teve 18 famílias assentadas, atualmente tem apenas oito, essa diminuição ocorreu devido a brigas internas entre lideranças dos 
assentados. Segundo relatos, desde a época de acampados, existia uma divisão entre as famílias devido a duas lideranças locais que possuíam pensamentos diferentes. Conforme aconteceu a formação do assentamento, um dos líderes foi expulso do assentamento pela outra liderança. De acordo com a liderança atual, o antigo líder se mostrava violento em suas posturas, gerando desunião entre os assentados.

Todas as famílias residem no assentamento. Trata-se de uma área que é resultado de uma ocupação que começou em 2009, porém as famílias só foram assentadas pelo Incra em 2010. Os assentados são oriundos do próprio município e de Aiuaba. A média de faixa etária dos assentados é alta, apresentando muitos idosos. Os jovens saem do assentamento devido às condições precárias de acesso e de infraestrutura. As más condições acabam influenciando o acesso à escolaridade, pois verificamos que o grau de escolaridade é muito baixo, 75\% dos agricultores pesquisados apresentam apenas o ensino fundamental incompleto. Desta forma, o nível de educação formal é ainda muito precário neste assentamento.

Devido às condições climáticas, os assentados produzem apenas para subsistência, praticam a pecuária, onde cada um tem caprinos e ovinos e, em certos casos, até bovinos. O assentamento é pequeno, mas tem um grande açude que, segundo os assentados, nunca secou, e é responsável pelo abastecimento do assentamento, como é relatado pelo assentado entrevistado número 4: "Esse açude é nossa vida, se ele secar, o assentamento acaba".

\section{- Assentamento Olho D’água}

O assentamento Olho D’ água está localizado no município de Várzea Alegre, microterritório do Cariri Central e possui 19 famílias assentadas. Todas residem no assentamento, a maioria é oriunda de uma antiga fazenda de gado leiteiro que existia no local onde hoje é o assentamento. As poucas famílias que não eram desta fazenda, são oriundas do próprio município ou do vizinho Cedro, com o qual o assentamento faz divisa. O assentamento foi implantado pelo Instituto Nacional de Colonização e Reforma Agrária - INCRA em 1996.

A média de idade dos assentados é de 35,5 anos, a juventude é bastante presente neste assentamento, colaborando junto com seus pais nas atividades agrícolas, porém verificamos que ao completarem 18 anos muitos decidem morar na cidade em busca de melhores condições de vida. Os jovens que ficam, que representam grande maioria, realizam a sucessão agropecuária, além de conseguirem seus lotes junto aos assentados, favorecendo assim seu desenvolvimento. O grau de escolaridade dos assentados entrevistados é baixo, poucos possuem ensino médio completo. A maioria possui o ensino fundamental incompleto, isto se dá pela falta de infraestrutura escolar no assentamento e pela necessidade de trabalharem 
desde muito cedo. Os assentados do Olho D’água produzem, assim como a maioria dos produtores familiares do Nordeste, milho e feijão, produzidos no período chuvoso, entre os meses de dezembro e março. Esses produtos são armazenados e consumidos por eles durante todo o ano, pouco é comercializado, apenas se comercializa quando se tem uma grande produção ou quando a demanda por esses produtos está muito alta.

\section{- Assentamento Baixa Grande}

O assentamento Baixa Grande está localizado no município Jati, microterritório do Cariri Leste. Com capacidade para até 170 famílias, este assentamento possui atualmente 144 famílias. Essas famílias são oriundas do próprio município, porém quatro dos 17 agricultores entrevistados são de outro estado, Pernambuco, já que o município de Jati fica no extremo sul do Ceará, fazendo divisa com este estado.

O assentamento foi implantado pelo INCRA em 2009. A média da idade dos entrevistados é de 36 anos. Neste assentamento há muitos adultos que não conseguiram ter acesso aos estudos formais em escolas quando eram mais jovens, consequentemente a escolaridade entre eles é muito baixa, assim como nos outros assentamentos pesquisados. Este fato ocorre por falta de infraestrutura nos assentamentos federais do Cariri, não havendo uma escola local. O grau de escolaridade poderia ainda ser aumentado com a presença de escolas com as disciplinas voltadas para a realidade do espaço rural, já que todos os assentados têm origem no meio rural e sua principal ocupação é a agropecuária, isto favoreceria o interesse pela escola.

O assentamento apresenta grande área de produção de palma forrageira e de milho, que são parte de projetos de produção agrícolas de órgãos de extensão rural e assistência técnica para alimentar a pecuária. $\mathrm{O}$ diferencial deste assentamento está na organização entre os assentados. Apesar de ser um assentamento com muitas famílias, há grandes áreas coletivas de plantio, prática não presente nos outros três assentamentos, onde o plantio individual é a realidade.

\section{INFRAESTRUTURA DOS ASSENTAMENTOS}

O assentamento Baixa Grande é um dos maiores em área do Ceará, com 8.489,99 ha. Poucos são os assentamentos resultantes do processo de reforma agrária com intervenção do INCRA neste território, isto é resultado de uma política de incentivo do governo do estado ao Programa Nacional de Crédito Fundiário, o qual incentiva agricultores familiares a adquirirem sua propriedade rural, sem a necessidade de organização por meio de movimentos sociais (ARRAIS, 2015).

Apenas o assentamento Baixa Grande, localizado em Jati, tem relação contínua com o Movimento dos Trabalhadores Rurais Sem Terra - MST. Tal fato foi 
observado durante a pesquisa de campo e ficou evidente que este assentamento tem grande mobilização social. Verificamos que grande parte da organização é oriunda de atividades junto ao MST, que realiza reuniões com a juventude deste assentamento e também atividades referentes à conscientização política dos assentados. A luta por direitos básicos como infraestrutura, saneamento, energia, acesso à cultura e lazer, sempre foi uma luta do MST, entendendo que a organização do assentamento é um dos pontos fundamentais para a sua consolidação.

Os assentamentos pesquisados estão locados em áreas distantes das sedes dos municípios, a sede do município de Antonina fica a $12 \mathrm{~km}$ do assentamento São João e a 18 km do São Paulo; enquanto a sede do município de Várzea Alegre fica localizada a $20 \mathrm{~km}$ do assentamento Olho D’água; e a sede do município de Jati fica localizada a $11 \mathrm{~km}$ do assentamento Baixa Grande.

As vias de acesso até os assentamentos são estradas sem pavimentação, o que dificulta o trânsito de veículos, principalmente nos meses chuvosos. Cabe ressaltar que serviços como bancos, hospitais e farmácias estão localizados na cidade. Verificamos que dos 47 assentados que foram entrevistados, somente cinco consideraram a via de acesso até o assentamento boa, dez consideraram esse acesso regular e trinta e dois dos entrevistados consideraram o acesso ao assentamento ruim, como relata o agricultor 11 do assentamento Olho D’água em Várzea Alegre: Se uma pessoa passar mal no período de chuva aqui, corre o risco dela morrer, pois não temos como levar à cidade, as estradas não passam carros baixos e o preço do frete até o hospital é muito caro (Agricultor 11).

De acordo com o INCRA (2010), em Pesquisa sobre a qualidade de vida nos assentamentos do país, $58 \%$ dos assentados estavam descontentes com as condições das estradas ou vias de acesso aos lotes e $56 \%$ descontentes com as condições de acesso a hospitais e postos de saúde. A realidade quanto à infraestrutura das estradas vem mudando pouco ao longo dos anos nos assentamentos rurais.

Das 47 famílias que foram aplicados os questionários, a totalidade possui casa de alvenaria, com telha de cerâmica e energia elétrica privada distribuída pela Companhia Energética do Ceará (COELCE), atualmente conhecida como Enel Distribuição Ceará.

Os assentamentos apresentam poucos equipamentos públicos. Verificamos que não há escolas em funcionamento em nenhum dos assentamentos, em alguns casos como nos assentamentos São João e Olho D'água há escolas, porém estão desativadas, e os prédios não são utilizados pelos assentados. Os jovens das comunidades são levados até as escolas mais próximas por ônibus das prefeituras. A educação no campo é um fator importante, porém ausente nos assentamentos rurais estudados.

As famílias assentadas apresentam trajetórias diferentes, todavia é comum 
entre elas o vínculo com a terra, sendo inclusive a principal ocupação de 38 dos 47 assentados pesquisados. Como citado por Leite et al (2004, p. 11), “a maior parte dos assentados vem do meio rural, residindo anteriormente no próprio município do assentamento ou em algum município vizinho, atuando desde sempre em atividades agrícolas".

Mesmo com essa origem rural, a evasão para cidades com maiores índices populacionais é bastante presente nos assentamentos federais do Cariri. Muitos jovens se deslocam até Juazeiro do Norte, centro urbano do território, em busca de melhores condições econômicas, pois entendem que a agricultura é uma atividade muito difícil para dela sobreviver, principalmente no Nordeste, com as condições climáticas desfavoráveis. A ausência de chuvas é considerada importante fator para a evasão rural, informação evidenciada pelas respostas dos assentados durante o trabalho de campo.

Quando nos referimos à infraestrutura de produção, os assentamentos não possuem áreas de armazenamento, também não apresentam nenhuma unidade de beneficiamento, onde poderiam beneficiar os alimentos e comercializarem junto às políticas públicas. Segundo Ortega (2003), o beneficiamento dos alimentos permite manter o valor nutricional e sua vida útil, além de agregar valor e fornecer estabilidade a produção. No assentamento Olho $\mathrm{D}^{\prime}$ agua a associação possui um trator que favorece a produção dos associados assentados e ainda é alugado para os produtores locais, com a renda revertida, mensalmente, para a associação.

\section{ASSISTÊNCIA TÉCNICA E EXTENSÃo RURAL NOS ASSENTAMENTOS}

O INCRA não possui escritório na região do Cariri, atendendo os assentados rurais apenas com visitas sazonais, na maioria das vezes motivadas por problemas cadastrais ou documentais.

Os serviços de assistência técnica e extensão rural são realizados por uma parceria estabelecida entre as secretarias de agricultura dos municípios e a Empresa de Assistência Técnica e Extensão Rural - EMATER/CE. Nos assentamentos estudados, apenas no município de Jati foi identificada uma rotina de visitas, com projetos em andamentos e assistências semanais. Os assentamentos localizados em Várzea Alegre e Antonina do Norte não recebem visitas frequentes dos agentes dos órgãos de ATER, conforme relatado pelos assentados pesquisados.

Os dados indicaram que 13 dos 16 assentados entrevistados no município de Antonina do Norte não recebem serviços de ATER. Em entrevista com o secretário de agricultura do município, este citou a falta de investimentos na secretaria, que não tem condições de atuar realizando este tipo de serviço nos assentamentos.

Antonina do Norte apresenta em seu quadro, na secretaria da agricultura, 
quatro profissionais com ensino superior, um deles é zootecnista, porém pouco atua nos assentamentos devido às condições de estrutura exigidas para este tipo de atuação. São exemplos de condições básicas para sua atuação: a qualificação técnica voltada a produção agrícola; um transporte para a locomoção, levando em consideração as vias de acesso até o assentamento; e materiais didáticos (apostilas e livros), voltados à realidade dos assentados.

Vale salientar que a multidisciplinaridade é um fator importante para a extensão rural, porém os profissionais graduados que trabalham nesta secretaria não possuem nenhum tipo de contato com a realidade dos agricultores assentados, atuando apenas nas questões administrativas. A secretaria municipal de agricultura de Antonina destaca-se negativamente no quesito transporte, por não possuir nenhum veículo disponível para os profissionais trabalharem na zona rural, dificultando assim os trabalhos de ATER.

Em observações durante a pesquisa de campo e transcritas para o diário de campo, percebemos que as indicações políticas são frequentes nas secretarias municipais de agricultura dos municípios pesquisados, o que pode dificultar os trabalhos de ATER, pois alguns profissionais podem não estar preparados para desempenharem as funções que os cargos requerem.

Por outro lado, o município de Jati está no outro extremo da situação até aqui apresentada, pois os dados indicaram que dos 17 entrevistados no assentamento Baixa Grande, 12 recebem assistência técnica semanalmente e participam de projetos vinculados à secretaria de agricultura do município e à EMATER/CE. Neste município há uma parceria entre esses órgãos para atender os assentados do Baixa Grande. Desta forma, um técnico agrícola promove as atividades de ATER, com compartilhamento de conhecimento e introdução de programas governamentais ligados à extensão rural. Projetos voltados à produção de ovinos e caprinos são a principal atividade de assistência técnica na comunidade Baixa Grande; de acordo com o secretário de agricultura do município de Jati, esse projeto será um meio para a introdução dos assentados no PNAE.

A ATER é ainda uma questão a ser resolvida nos assentamentos rurais, a falta deste tipo de serviço não contribui para o desenvolvimento rural e muitas vezes pode impossibilitar a participação dos assentados em politicas públicas de grande importância, como por exemplo, o PNAE, pois os assentados sequer podem ter acesso a esse tipo de informação, uma vez que a ATER tem também a função de organizar os agricultores para o acesso às políticas públicas a eles direcionadas.

\section{Programa Nacional de Alimentação Escolar nos assentamentos}

As dificuldades em infraestrutura e a falta de acesso a serviços de ATER 
comprometem também a comercialização dos produtos dos agricultores familiares assentados, pois tornam a produção e a logística de comercialização mais cara, devido a vários fatores, como por exemplo, o aumento do custo de deslocamento da produção para a venda.

De acordo com os assentados, o preço de fretes para escoar a produção até a cidade quase dobra nos meses de chuva devido às condições das vias de acesso. Outro fator apontado que tem contribuído para o aumento dos custos, é a falta de assistência técnica, pois os assentados não contam com apoio apropriado e acabam gastando mais do que o necessário na sua produção. No assentamento Olho D’ água, por exemplo, os assentados nunca tinham ouvido falar em defensivos naturais, utilizando apenas agroquímicos. Fatores como estes geram maior custo de produção, tornando o produto vendido mais caro no ato da comercialização, diminuindo a procura e consequentemente diminuindo a renda familiar dos assentados.

Os assentados dos municípios de Jati e de Antonina do Norte não comercializam seus alimentos junto ao PNAE. Em Várzea Alegre, somente dois assentados comercializavam no PNAE. Apesar da maioria dos assentados do município de Jati receber serviços de ATER, eles não conseguem comercializar sua produção junto ao programa, pois estes serviços tiveram início em 2018. Os assentados ainda não haviam logrado organizar sua produção e logística para fornecer sua produção à alimentação escolar. À época da pesquisa, os agentes de ATERestavam atuando junto aos agricultores para viabilizar a inserção da produção dos assentados no PNAE.

Em muitos casos a ineficiência das políticas públicas entre assentados decorre da falta investimento, de divulgação e auxílio técnico (BARONE, 2000; MARTINS, 2003; FERRANTE; BARONE, 2004).

Quando ampliamos a análise para a agricultura familiar, não nos restringindo aos assentamentos, percebemos que os municípios que possuem assentamentos não conseguiram cumprir a lei no que concerne à inserção de alimentos oriundos da agricultura familiar de 2013 a 2016 (Tabela 2).

Os dados disponíveis abrangem somente até o ano de 2016, porém em conversas com os secretários de educação e de agricultura dos municípios pesquisados não se nota uma perspectiva de evolução. Apenas no município de Jati existe um projeto de caprinovinocultura onde foram fornecidas matrizes de baixo custo para a produção de carne no sentido de ativar a participação de assentados e agricultores familiares no PNAE.

Em entrevista com agentes locais da Secretaria Municipal de Educação, verificamos que o município de Jati apresenta pequeno número de agricultores familiares ligados ao PNAE, sendo que apenas três agricultores familiares (não assentados) comercializam seus alimentos para serem incorporados à merenda 
escolar. Em Antonina do Norte, oito agricultores comercializam junto ao PNAE, e, em Várzea Alegre, 63 agricultores comercializam seus alimentos para o PNAE. Os dois agricultores familiares assentados que comercializam junto ao PNAE são do assentamento Olho D'água, do município de Várzea Alegre. Esses assentados tomaram conhecimento do Programa por comunicação com a prefeitura, fazia um ano que atuam junto ao PNAE, e há quatro anos comercializam seus produtos para o Programa de Aquisição de Alimentos - PAA.

Verificamos que não houve uma forma de comunicação para divulgação do PNAE, porém esses dois assentados que participam deste programa tinham proximidade com os extensionistas da Secretaria de Agricultura e assim tiveram acesso a informações sobre o PNAE. Em nenhum momento foi realizada reunião com os assentados ou uma divulgação mais ampla por meios digitais ou panfletos que pudesse abranger os demais assentados. Percebemos que esses agricultores já estavam organizados na comercialização com o mercado institucional, o que facilitou o seu acesso ao programa.

Porém, as dificuldades com a logística se fazem presentes, uma vez que a via de acesso entre o assentamento e a sede do município é muito precária. Apesar dessas dificuldades, os assentados que participam do PNAE se dizem muito satisfeitos com a participação no programa, apesar as dificuldades apresentadas anteriormente.

Os assentados que participam do PNAE são responsáveis pelo transporte da produção até o município, sendo os alimentos entregues todas as terças-feiras na central de abastecimento do município de Várzea Alegre. Os assentados, junto com os demais agricultores do município que entregam seus alimentos ao PNAE, participam de reuniões com a Secretaria de Educação, órgão responsável pela execução do PNAE no município.

Tabela 2 - Porcentagem de compra de produtos da agricultura familiar nos municípios do Território da Cidadania do Cariri, onde se localizam os assentamentos estudados.

\begin{tabular}{lllll}
\hline Entidade Executora & $\mathbf{2 0 1 3}$ & $\mathbf{2 0 1 4}$ & $\mathbf{2 0 1 5}$ & $\mathbf{2 0 1 6}$ \\
\hline Pref. Mun. de Antonina do Norte & $20 \%$ & $18 \%$ & $27 \%$ & $21 \%$ \\
\hline Pref. Mun. de Jati & $17 \%$ & $21 \%$ & $31 \%$ & $31 \%$ \\
\hline Pref. Mun. de Várzea Alegre & $33 \%$ & $40 \%$ & $20 \%$ & $18 \%$ \\
\hline
\end{tabular}

Fonte: Elaborado pelos autores a partir dos dados do FNDE (2018).

Para os dois assentados que comercializam junto ao PNAE, o programa não 
tem contribuído ou incentivado a transição orgânica/agroecológica. Segundo eles, no assentamento em que moram existem muitas pragas que dificultam a produção, e nunca tentaram produzir sem o uso de agrotóxicos, como relata o assentado número 22: "Se eu não colocar veneno, eu não consigo produzir nada, nem para comer". Esses assentados não modificaram sua produção, durante o ano da pesquisa, estão produzindo os mesmos alimentos que antes, mas pensam que para a próxima chamada pública, meio pelo qual são cadastrados e conseguem comercializar junto ao programa, devem produzir alimentos diferentes, para que consigam comercializar mais. Durante a pesquisa de campo, notamos que esse pensamento de diversificação possui viés apenas econômico, não tendo relação direta com alguma preocupação ecológica que a diversificação poderia gerar.

As associações de agricultores familiares são presentes nos assentamentos federais do território da cidadania do Cariri, mas ainda não conseguem atuar em conjunto no Programa Nacional de Alimentação Escolar. A ideia do associativismo vinculado às politicas públicas pode ser uma solução para problemas relacionados à periodicidade da entrega, podendo ser realizado um planejamento com entregas feitas por vários produtores via associação.

Os assentados se consideram unidos e citam que a associação atende a seus interesses particulares. Os assentamentos Baixa Grande e Olho D'água atuam em mutirão, que é conhecido por eles como trabalho " coletivo" ou em coletividade, que é quando os assentados se unem para uma atuação em conjunto, seja relacionado a produção ou a infraestrutura do assentamento, ocorrendo ao menos uma vez na semana. No assentamento Baixa Grande, há uma área coletiva com a produção de palma forrageira; no assentamento Olho d’Água, o dia da coletividade é voltado ao assentamento em si, através da construção de estradas, cercas, atividades mais voltadas ao bem estar do assentamento. $\mathrm{O}$ trabalho em coletivo fortalece o assentamento das baixas condições de produção, sejam voltados a infraestrutura, ausência de informações e difíceis condições climáticas.

As condições edafoclimáticas geram a pouca produção agrícola nos assentamentos, fazendo com que os assentados produzam, majoritariamente, para a subsistência. Esse modelo de produção, para o autoconsumo, não motiva os assentados a produzirem para o PNAE, que exige uma regularidade de entrega, com isso as associações que atuam nos assentamentos se limitam apenas a vendas locais e não se envolvem com políticas públicas.

\section{CONSIDERAÇões FINAIS}

O Programa Nacional de Alimentação Escolar tem potencial para a promoção do desenvolvimento rural nos municípios do território da cidadania do Cariri, 
porém não houve adesão por parte dos assentados dos assentamentos federais deste território devido às dificuldades de infraestrutura e carência de serviços de ATER. Apenas dois agricultores assentados, ambos do assentamento Olho D'água, do município de Várzea Alegre, fornecem alimentos ao programa.

A baixa adesão pode estar vinculada às questões de infraestrutura, uma vez que as condições físicas das estradas são muito ruins e os assentamentos ficam distantes das sedes dos municípios, o que encareceria a entrega semanal dos alimentos. A questão da falta de assistência técnica e extensão rural pode também ser um fator que explica a baixa adesão ao Programa, pois muitas vezes os assentados sequer sabem da existência do PNAE.

A falta de informação quanto o PNAE gera descrenças entre os assentados, pois acreditam que este programa não apresenta benefícios e somente dificuldades, impossibilitando o desenvolvimento dos assentamentos e prejudicando o seu trabalho, porém os agricultores que atuam junto ao PNAE sabem que a garantia de comercialização cria um cenário de maior estabilidade para as famílias assentadas, gerando aumento da renda e fortalecendo a agricultura familiar local.

A condição ambiental é fator que dificulta a inserção dos assentados rurais no PNAE, já que os assentamentos não apresentam, em sua maioria, segurança hídrica para a produção agrícola, devido aos períodos de déficit pluviométricos, gerando problemas de seca que são características nas zonas semiáridas do Nordeste.

Desta forma, para viabilizar o acesso dos agricultores assentados, torna-se necessário o investimento público nos serviços de assistência técnica e extensão rural, que possa promover a melhor organização dos agricultores para o acesso ao PNAE, bem como contribuir para a resolução de problemas de infraestrutura (especialmente aqueles relacionados às estradas) e de produção.

Os serviços de assistência técnica e extensão rural são fundamentais para o acesso dos agricultores assentados ao PNAE. A atuação de extencionistas rurais favorece a produção agropecuária, mesmo em locais cujas condições edafoclimáticas são severas, pois pensar, de forma conjunta, em estratégias para solucionar este problema faz parte da ação extensionista. Assim, problemas de infraestrutura, como melhores estradas, escolas em assentamentos, construção de açudes e cisternas, podem ser contornados com a presença da ATER pública e gratuita. $\mathrm{O}$ acesso a esses serviços, assim como a políticas públicas gera resultados positivos para os agricultores assentados e também para os municípios, pois promove a economia local e, consequentemente, o desenvolvimento nessas localidades.

\section{Agradecimentos}

Os autores agradecem a Capes - Coordenação de Aperfeiçoamento de Pessoal 
de Nível Superior pelo financiamento por meio da bolsa de mestrado do primeiro autor.

\section{REFERÊNCIAS}

ANDRADE, M. C. de. A Questão do Território no Brasil. $2^{\circ}$ Ed. São Paulo - Recife: HUCITEC / IPESPE, 2004.

. Modernização e Pobreza: A expansão da agroindústria canavieira e seu impacto ecológico e social. São Paulo: Editora UNESP, 1994.

ARRAIS, A. M. A. C. Convivência Sustentável com o Semiárido: análise do impacto das políticas públicas na agricultura familiar. 2015. 193 p. Dissertação (Mestrado em Desenvolvimento regional sustentável). - Universidade Federal do Cariri, Juazeiro do Norte - Ce, 2015.

BANDEIRA, L. A. M. O feudo: a Casa da Torre de Garcia d'Ávila: da conquista dos sertões à independência do Brasil. Rio de Janeiro: Civilização Brasileira, 2000. $601 \mathrm{p}$.

BARONE, L. A. A Assistência Técnica aos Assentamentos Rurais do Estado de São Paulo: da Política Reativa ao Vazio de Projeto. Revista Retratos de Assentamentos, n. 7, pp. 47-64, 2000.

BARREIRA, C.. Trilhas e atalhos do poder: conflitos sociais no Sertão. Rio de Janeiro: Editora Rio Fundo,1992. 193p.

BERGAMASCO,S.M.P.P. A realidade dos assentamentos rurais por de trás dos números. In: Estudos Avançados, São Paulo, vol.11, n.31, set-dez, 1997. Disponível em: http://www.scielo.br/scielo.php?script=sci_arttext\&pid=S0103-40141997000300003. Acesso em: 20 Maio 2017.

BERGAMASCO, S.M.P.P.; NORDER, L.A.C. Os impactos regionais dos assentamentos rurais em São Paulo (1996-1997). In: A formação dos assentamentos rurais no Brasil: processos sociais e políticas públicas. Medeiros, L.S. de \& Leite, S.(Orgs.). Porto Alegre/Rio de Janeiro: Ed. Universidade/UFRGS/CPDA, 1999. 
BRASIL. Ministério do Desenvolvimento Agrário (MDA). Plano territorial de Desenvolvimento rural sustentável: território cidadania do cariri. Fortaleza: Instituto Agropolos do Ceará, 2010.

BRASIL. Lei $\mathrm{n}^{\mathbf{0}} \mathbf{1 1 . 9 4 7}$, de 16 de junho de 2009. Dispõe sobre o atendimento da alimentação escolar e do Programa Dinheiro Direto na Escola aos alunos da educação básica; altera as Leis nos 10.880, de 9 de junho de 2004, 11.273, de 6 de fevereiro de 2006, 11.507, de 20 de julho de 2007; revoga dispositivos da Medida Provisória no 2.178-36, de 24 de agosto de 2001, e a Lei no 8.913, de 12 de julho de 1994; e dá outras providências. Diário Oficial [da] República Federativa do Brasil, Brasília, DF, 17 jun. 2009.

BRÍGIDO, J.Ceará (Homens e Fatos). Fortaleza: Demócrito Rocha, 2001.

BURLANDY, L. A construção da política de segurança alimentar e nutricional no Brasil: estratégias e desafios para a promoção da intersetorialidade no âmbito federal de governo. Ciência \& Saúde Coletiva, Rio de Janeiro, v. 14, n. 3, p. 851860, maio/jun. 2009.

CAMARGO, R.A.L.; SOUZA, J.P.G.T.; FIGUEIREDO, D.S.; GULLA, M.V.; JACOPINI, N.Q. Caracterização dos assentados do nordeste paulista que participam do PAA e PNAE. In: CONGRESSO DA SOCIEDADE BRASILEIRA DE ECONOMIA, ADMINISTRAÇÃO E SOCIOLOGIA RURAL, 51., 2013, Belém. Anais. Belém: Sober, 2013.

CORÁ, M.A.J; BELIK, W. Projeto Nutre SP: análise da inclusão da agricultura familiar na alimentação escolar no estado de São Paulo. São Paulo: Instituto Via Pública, 2012.

CRUZ, Suely Ferreira da; ASSIS, Thiago Rodrigo de Paula. Contribuições de três organizações para a comercialização da agricultura familiar no PNAE, no território sul litorâneo do Espírito Santo. Interações (Campo Grande), Campo Grande, v. 20, n. 3, p. 737-752, Sept. 2019 . http://dx.doi.org/10.20435/inter. v20i3.2063.

DENARDI, R. A. Agricultura familiar e políticas públicas: alguns dilemas e desafios para o desenvolvimento rural sustentável. Agroecologia e desenvolvimento 
rural sustentável, Porto Alegre, v. 2, n. 3, p. 56-62, 2001.

ESPLAR. Quadro recente da agricultura e trajetória dos movimentos sociais no estado do Ceará - primeira parte. Fortaleza. 1991. Apud Ceará. GOVERNO DO ESTADO. II Plano de Reforma Agrária. Fortaleza. INCRA - CE. 2014.

FERRANTE, V.L.S.B.; BARONE, L.A. A difícil semeadura: o trabalho na terra e a ressocialização das famílias assentadas em projetos de reforma agrária. In R. A. Scopinhoet alii (Orgs.), Velhos Trabalhos, Novos Dias: modos atuais de inserção de antigas atividades laborais. Fortaleza/São Carlos, EdUFC/EdUFSCar, pp. 112134, 2004.

FEUSER, N.S.A. SILVEIRA; C.V. MARQUES, B. M. O pronaf na percepção de produtores rurais do assentamento Itamarati Em Ponta Porã/MS. Revista desenvolvimento, fronteiras e cidadania, vol.3, n.1, p.27-41. Março de 2019.

FINATTO, Roberto Antônio; CORRÊA, Walquiria Kruger. Desafios e perspectivas para a comercialização de produtos de base agroecológica - $\mathrm{O}$ caso do município de Pelotas/RS. Revista Brasileira de Agroecologia, [S.l.], v. 5, n. 1, mar. 2010. ISSN 1980-9735.

FUNDO NACIONAL DE DESENVOLVIMENTO DA EDUCAÇÃO (FNDE). Programa Nacional de Alimentação Escolar - Dados da Agricultura Familiar. Disponível em: http://www.fnde.gov.br/programas/pnae/pnae-consultas/ pnae-dados-da-agricultura-familiar. Acesso em: 20/05/2018.

GIL, A. C. Como elaborar projetos de pesquisa. - 4. ed. - São Paulo : Atlas, 2002.

INSTITUTO DE COLONIZAÇÃO E REFORMA AGRÁRIA. Pesquisa Sobre a Qualidade de Vida, Produção e Renda dos Assentamentos da Reforma Agrária. 2010. Disponível em: http://www.incra.gov.br/media/reforma_agraria/ questao_agraria/pqra\%20\%20apresentao.pdf. Acesso em Set. 2017.

Assentamentos Rurais na definição do INCRA. Disponível em: http://www.incra.gov.br/assentamento. Acesso em: fev. 2018.

IBGE - Instituto Brasileiro de Geografia e Estatística. Censo Agropecuário. 2017. 
Disponível: <http:https://censos.ibge.gov.br/agro/2017/>. Acesso: Set. 2018.

LAMARCHE, H. (coord.). A agricultura familiar: comparação internacional. Vol. I: umarealidade multiforme. Campinas: Editora da Unicamp, 1993.

LEITE, S.; HEREDIA, B.; MEDEIROS, L.; PALMEIRA, M.; CINTRÃO, R. Impacto dos assentamentos. Um estudo sobre o meio rural brasileiro. São Paulo SP: Fundação Editora da Unesp, 2004.

MARTINS, J.de S. O Sujeito Oculto: Ordem e Transgressão na Reforma Agrária. Porto Alegre, EdUFRGS, 2003.

MELÃO, I. B. Produtos sustentáveis na alimentação escolar: o PNAE no Paraná. Caderno IPARDES, Curitiba, v. 2, n.2, p. 87-105, jul./dez. 2012.

ORTEGA, Enrique. Ecologia com visão sistêmica: $\mathbf{O}$ sistema de produção de alimentos. DEA/FEA/Unicamp. 2003. Disponível em: https://www.unicamp.br/fea/ ortega/ecologia/desafio-6.htm. Acesso em: 04 de Abri de2019.

PETRONE, P. Contribuição ao Estudo da Região do Cariri, no Ceará. Boletim Paulista de Geografia, São Paulo, n. 19, p.3-28, março de 1955.

PRETTO, J. M. HORN, C.H. Uma avaliação do PRONAF no período 1995-2018. COLÓQUIO - Revista do Desenvolvimento Regional - Faccat, Taquara/RS - v. 17, n. 1, jan./mar. 2020.

SAMBUICHI, R. H. R. et al. (Org). Políticas Agroambientais e Sustentabilidade: desafios, oportunidades e lições aprendidas. Brasília: Ipea, 2014.

SANTOS, Alessio Moreira dos; MITJA, Danielle. Agricultura familiar e desenvolvimento local: os desafios para a sustentabilidade econômico-ecológica na comunidade de Palmares II, Parauapebas, PA. Interações (Campo Grande), Campo Grande, v. 13, n. 1, p. 39-48, June 2012. http://dx.doi.org/10.1590/S151870122012000100004 .

SANTOS, G. E. de O. Cálculo amostral: calculadora on-line. Disponível em: $<$ http://www.calculoamostral.vai.la $>$. Acesso em: 02 de Jul de 2018. 
SARAIVA, E.B; SILVA, A.P.F da; SOUZA, A.A. de; CERQUEIRA, G.F; CHAGAS, C.M.S.; TORAL, N. Panorama da compra de alimentos da agricultura familiar para o Programa Nacional de Alimentação Escolar. Revista Ciência \& Saúde Coletiva, Rio de Janeiro, v. 18, n. 4, p. 927-936, 2013.

SCHNEIDER, S.; GERHARDI, T.; TRICHES, R. M. Alimentação escolar e agricultura familiar: reconectando o consumo à produção. In: CONGRESSO INTERNACIONAL DE LA RED SIAL, 4., 2008, Mar Del Plata. Anais eletrônicos... Mar Del Plata: Inta, 2008. Disponível em: https://inta.gob.ar/balcarce. Acesso em: 12 jan. 2018.

SILVA, D.B.P.; BACCARIN, J.G.; ALEIXO, S.S.; FILIPAK, A. Os agentes sociais e o Programa Nacional de Alimentação Escolar (PNAE): a percepção dos agricultores familiares. In: ENCONTRO INTERNACIONAL PARTICIPAÇÃO, DEMOCRACIA E POLÍTICAS PÚBLICAS: APROXIMANDO AGENDAS DE AGENTES, 23 a 25 de abril de 2013, Araraquara. Anais. Rio Claro, 2013.

SOUZA-ESQUERDO, V.F. de; BERGAMASCO, S.M.P.P. Análise sobre o acesso aos programas de políticas públicas da agricultura familiar nos municípios do circuito das frutas (SP). Rev. Econ. Sociol. Rural [online]. 2014, vol.52, suppl.1, pp.205222. ISSN 0103-2003. http://dx.doi.org/10.1590/S0103-20032014000600011.

SPAROVEK, G. A qualidade dos assentamentos de reforma agrária brasileira. Páginas \& Letras. São Paulo, SP. 2003.

TRICHES, R. M.; SCHNEIDER, S. Alimentação escolar e agricultura familiar: reconectando o consumo à produção. Saúde e Sociedade, São Paulo, v. 19, n. 4, p. 933-945, out./dez. 2010.

VILLA REAL, L. C.; SCHNEIDER, S. O uso de programas públicos de alimentação na reaproximação do pequeno produtor com o consumidor: o caso do Programa de Alimentação Escolar. Estudo \& Debate, Lajeado, v. 18, n. 2, p. 57-79, 2011. 